\title{
RENT DISSIPATION IN REPEATED ENTRY GAMES: SOME NEW RESULTS
}

\author{
JEAN-PIERRE PONSSARD
}

\section{CESIFO WORKING PAPER NO. 1186 \\ CATEGORY 9: INDUSTRIAL ORGANISATION \\ MAY 2004}

Presented at CESifo Area Conference on Industrial Organisation, March 2004 


\title{
RENT DisSiPATION IN REPEATED ENTRY GAMES: SOME NEW RESULTS
}

\begin{abstract} Several economic illustrations are discussed.

JEL classification: C73, D43, L12.

Keywords: rent dissipation, Markov equilibria, hit and run.

\author{
Jean-Pierre Ponssard \\ Laboratoire d'Econométrie \\ CNRS and Ecole Polytechnique \\ I rue Descartes \\ 75005 Paris \\ France \\ ponssard@poly.polytechnique.fr
}

Two player infinitely repeated entry games are revisited using a new Markov equilibrium concept. The idea is to have an incumbent facing a hit and run entrant. Rent dissipation no longer necessarily holds. It will not when competition is tough in case of entry. Similarities and differences with previous approaches are analyzed.

Previous versions of this paper have been presented at Core (Louvain), Cirano (Montreal), CMM (Santiago de Chile), Etape (Paris), Hec (Jouy en Josas), Idei (Toulouse), IHP (Paris) and SSE (Stockholm). I thank David Encaoua, Denis Gromb, Rim Lahmandi-Ayed, Rida Laraki, Jean François Laslier, Anne Perrot, Patrick Rey, David Sevy, Nicolas Vieille and the participants to the seminars for helpful comments and suggestions. 


\section{Introduction ${ }^{1}$}

This paper revisits the dynamics of potential competition in a natural monopoly context. In such situations an incumbent is repeatedly facing an entrant. Rent dissipation ordinarily prevails (see among others Fudenberg and Tirole, 1987 and Wilson, 1992). The intuitive idea behind rent dissipation is a rational expectations argument (Farrell, 1986). In Maskin and Tirole (1988) and in Ponssard (1991) a proper game analysis confirms the rational expectations intuition. These results provide some formal grounds to contestability theory (Baumol et al., 1982).

Contestability is an important benchmark in applied industrial organization. Originally designed for the airline industry it has been applied to many sectors such as telecoms or electricity. The main idea is to restructure the industry to reduce the length of commitments and the possible sunk costs, which is 
equivalent to have the discount factor go to one in a repeated entry game. Other economic characteristics play no role.

Many economists have challenged this view (for survey articles see Brock, 1983 or Shepherd, 1984). Two criticisms are directly relevant for this paper: why should the incumbent remain passive against a hit an run strategy? why is it that the intensity of competition in case of entry plays no role in the argument? The first question refers to a theorical issue which can only be handled in a game framework. The second question (first pointed out in Dasgupta and Stiglitz, 1986) refers to empirical matters. Indeed, Sutton (p. 35, 1991) provided ample evidence that "a very sharp fall in price suffices to deter entry and maintain a monopoly outcome".

This paper provides a game theoretic formalization of hit and run strategies in an infinite horizon: if the incumbent makes a mistake, the equilibrium path is such that the entrant comes in, makes some money and then leaves. Equilibrium paths are such that the intensity of competition in case of entry plays a major role $^{2}$.

More specifically, rent dissipation need not necessarily prevail. ${ }^{3}$ In this approach rent dissipation depends on the monopoly rent relative to the cost of entry: when this ratio is high rent dissipation occurs and when it is low it does not. Consequently, the tougher the competition in case of entry the more likely rent dissipation fails to hold.

In addition to rent dissipation, selection is also analyzed. Selection means that only the more efficient firm can remain a permanent incumbent (selection was introduced in Gromb et al., 1997, in which finitely repeated asymmetric entry games were first analyzed). Selection is an important economic property to look for since it encourages innovation and the search for competitive advantage. In a dynamic context it seems preferable to the static productive efficiency criteria. The empirical results reported by Scherer (1992) and Gerovski (1995) indeed show that most entries occur after large innovations. It is proved that equilibrium paths satisfy selection if the asymmetry between the two firms is high enough.

These results on rent dissipation and on selection can be conveniently summarized through a new and interesting taxonomy of competitive situations. Depending on its economic characteristics, a given situation may be qualified as typical of:

excess-competition: if a more efficient incumbent were to choose to deter entry forever, it would have to dissipate all of its profits;

under-competition: a less efficient incumbent can deter entry forever and make stationary positive profits;

selection: a less efficient incumbent is not able to deter entry forever and

\footnotetext{
${ }^{2}$ There are formalizations of this idea in the context of two stage games (see for instance Henry, 1988, Sutton, 1991 chap 2, or d'Aspremont and Motta, 2000) but to the author's knowledge none in the infinite horizon context. In the two stage models, the firms cumulative pay-offs are zero by construction.

${ }^{3}$ See Boyer et al., 2003, for a recent contribution in which rent dissipation does not prevail. Their argument is based on capacity constraints and is unrelated to the current discussion.
} 
make stationary positive profits, but a more efficient incumbent may.

At the formal level, the adopted Markov equilibrium concept extends the one used by Maskin and Tirole (1988). ${ }^{4}$ The idea is to relax the stationarity assumptions which they impose on the strategies. This relaxation is motivated by the results obtained in Gromb, Ponssard and Sevy (1997). ${ }^{5}$ There it was shown that when one firm is more efficient than the other, at equilibrium, the less efficient firm cannot remain a permanent incumbent in a long enough game. This suggests that the stationarity assumption is too strong and is the reason for the drawback of the MT approach pointed out in Lahmandi et al. (1996) namely, that the less efficient firm can remain a permanent incumbent and, moreover, that its stage rent is higher than what the more efficient firm would obtain were it the permanent incumbent. Yet, the GPS approach, when extrapolated to infinitely repeated games, has drawbacks of its own. The issue remained open.

The paper is organized as follows. Section 2 introduces the class of infinitely repeated entry games under study. Various solution concepts may be used to analyze these games. In section 3 the new Markov solution concept is defined. Similarities and differences with previous appraoches are detailed in the appendix. Section 4 studies the mathematical properties of the proposed solution concept: the given finite time horizon for incumbency of the hit and run firm is the key parameter. It is proved that when an equilibrium exists it is necessarily unique, that this firm would prefer to play in a game in which its given time as an incumbent is as long as possible but that when this given time exceeds some bound such an equilibrium may no longer exist. Whenever there is no such bound the situation is one of rent dissipation. A necessary and sufficient condition for such a bound to exist is obtained. In section 5, the conditions for rent dissipation are interpreted and a new taxonomy of situations is introduced, economic illustrations are detailed in the appendix. Section 6 concludes with open questions that should be studied to improve our understanding of the proposed solution concept.

\section{The game $\Gamma_{\infty}^{\delta}$}

Various game forms may be used to capture the idea of short run commitments in a natural monopoly context. For convenience, our model is very similar to the one introduced in GPS. Denote $\Gamma_{\infty}$ such an entry game.

Denote the two firms player 1 and player 2. Let $i$ be anyone of the two players and $j \neq i$ be the other one.

The game $\Gamma_{\infty}$ is constructed from two one stage Stackelberg entry games, denoted $G(1)$ and $G(2)$. The game $\Gamma_{\infty}$ consists of a sequence of such one stage games $\left(G\left(i^{1}\right), G\left(i^{2}\right), \ldots, G\left(i^{k}\right) \ldots.\right)$ in which any $i^{k}$ may be either 1 or 2 depending on the actual moves selected along the way ${ }^{6}$.

\footnotetext{
${ }^{4}$ to be later refered to as the MT approach. Originally designed for entry games, this approach has been extended to any extensive game (Maskin and Tirole, 2001).

5 to be later refered to as the GPS approach.

${ }^{6}$ Strictly speaking the game under study is not a reapeated game since the stage game varies
} 
Each game $G(i)$ is played as follows:

step 1: the first player to move is player $i$, it is called the incumbent, player $i$ may either select a move $x_{i}$ in $\Re$ or move out;

step 2a: if player $i$ selects $x_{i}$ at step 1 then player $j$ may either select in (with respective payoffs for $i$ and $j: d_{i}\left(x_{i}\right),-C_{j}\left(x_{i}\right)$ ) or out (with respective payoffs : $\left.v_{i}\left(x_{i}\right), 0\right)$;

step 2b: if player $i$ selects out at step 1 then player $j$ may either select a move $x_{j}$ in $\Re$ or move out;

step 3 : if player $i$ selects out at step 1 and player $j$ selects $x_{j}$ at step $2 \mathrm{~b}$ then player $i$ may either select in (with respective payoffs : $-C_{i}\left(x_{j}\right), d_{j}\left(x_{j}\right)$ ) or out (with respective payoffs : $0, v_{j}\left(x_{j}\right)$ );

step 4: if player $i$ selects out at step 1 and player $j$ selects out at step $2 \mathrm{~b}$ then the game $\Gamma_{\infty}$ stops (with respective payoffs : 0,0 ).

Moreover the actual play of $G(i)$ determines the incumbent in the next $G\left(i^{\prime}\right)$ to be played :

- player $i^{\prime}$ is again player $i$ if this sequence is $\left(x_{i}\right.$, out $)$ or (out, $\left.x_{j}, i n\right)$;

- player $i^{\prime}$ is player $j$ if the sequence is $\left(x_{i}, i n\right)$ or $\left(\right.$ out,$x_{j}$, out).

- Denote $i^{+}(i)$ the next stage incumbent determined according to this transition rule.

The payoffs in the game are the sum of the stage payoffs using a discounted factor $\delta$. Attention is focued on $\delta$ close to 1 .

This completely specifies $\Gamma_{\infty}^{\delta}$.

The functions $v_{i}, C_{i}, d_{i}$ respectively stand for stage monopoly profits, entry costs and exit payoffs. For $i \in(1,2)$ it is assumed that $v_{i}$ is strictly increasing, $C_{i}$ strictly decreasing and $d_{i}$ non positive.

For $\Gamma_{\infty}^{\delta}$ to be of economic interest it is assumed that :

$$
\begin{aligned}
& C_{j}^{-1}(0)>v_{i}^{-1}(0) \\
& C_{i}^{-1}(0)>v_{j}^{-1}(0)
\end{aligned}
$$

The first inequality means that the static "limit price" of player $i, C_{j}^{-1}(0)$, should be higher than player $i$ 's "average cost", $v_{i}^{-1}(0)$, otherwise player $i$ is definitely barred from entry (the situation is one of "bockaded entry"). Similarily for player $j$.

For mathematical convenience it will be further assumed that the functions $v_{i}$ and $C_{i}$ have derivatives and that these derivatives are uniformly bounded away from zero and from infinity. It is believed that this technical assumption may be relaxed without affecting the results.

Two classes of games shall be of special interest.

The class of symmetric entry games in which $v_{1}=v_{2}$ and $C_{1}=C_{2}$. The economic issue is rent dissipation : at equilibrium, does the stage payoff of the incumbent $v_{i}\left(x_{i}\right)$ converge to zero when the discount factor goes to one ?

among two distinct ones. However, folk theorems apply and some form of Nash selection is required. 
The class of asymmetric entry games in which $v_{1}=v_{2}+\Delta f$ in which $\Delta f$ is a constant, and $C_{1}=C_{2}$. The economic issue is selection: suppose $i^{1}=2$, then is it true that for all $\Delta f>0$, at equilibrium, player 1 is the long run incumbent i.e., for all $k \geq k^{*}, i^{k}=1$, whatever the discount rate close enough to one ?

\section{Interpretation}

Consider a standard Stackelberg model such as Dixit (1980). The leader commits to some move $q_{L}$ then the follower reacts with $q_{F}$. The entry barrier is constructed in such a way that the profit of the follower is not positive. Denote the two players profits $h_{L}\left(q_{L}, q_{F}\right)$ and $h_{F}\left(q_{L}, q_{F}\right)$. With our notations $C_{F}\left(q_{L}\right)=$ $-\max _{q_{F}} h_{F}\left(q_{L}, q_{F}\right)$ and $v_{L}\left(q_{L}\right)=h_{L}\left(q_{L}, q_{F}\right)$ when the follower does not enter. In a static model the optimal entry preventing commitment maximizes $v_{L}\left(q_{L}\right)$ under the constraint $\max _{q_{F}} h_{F}\left(q_{L}, q_{F}\right) \leq 0$ that is, $C_{F}\left(q_{L}\right) \geq 0$. In the context of a repeated entry game with short term commitments this is not enough since the follower takes into account the future stream of profits he could obtain acting as a leader in the next Stackelberg game, etc. There are several ways to precisely define such a dynamic entry game (Eaton and Lipsey, 1980, Maskin and Tirole, 1988, Ponssard, 1991).

The selected game form has several advantages: the endogeneity of leadership is key, the game has no simultaneous moves which avoids multiplicity of stage equilibria, it is easier to track than alternate move models, players are encouraged to move in to avoid stopping the game and the results can be extended with some effort to the other game forms.

\section{The selected Markov equilibrium concept}

The game $\Gamma_{\infty}^{\delta}$ has many Nash equilibria ranging from predatory behavior (one player behaves as an unconstrained monopolist if incumbent and always moves in if not, and the other always stays out) to collusive behavior (the two players alternate as incumbent using tit for tat as a threat). Such equilibria are not illustrative of hit and run competition.

This section proposes a new Markov equilibrium concept, to be denoted as SME for selected Markov equilibrium, among more general Markov approaches.

Markov strategies depend on the way the state variable is defined. The state variable precises the stakes of a given stage game $G$. It of course says who is the incumbent. A time variable will be included in the state variable to capture the non stationarity of the hit and run behavior.

The general Markov approach

Let

- $t$ be the discrete time variable;

- $\theta$ be the state variable, $\theta=(i, t)$ which means that $G(i)$ is the stage game to be played;

- $\left(z_{1}^{\theta}, z_{2}^{\theta}\right)$ stand for the decisions in $G(i)$ given $\theta$ and $\left(Z_{1}, Z_{2}\right)$ stand for the strategies ; 
- $G_{1}^{\theta}\left(z_{1}^{\theta}, z_{2}^{\theta}\right)$ and $G_{2}^{\theta}\left(z_{1}^{\theta}, z_{2}^{\theta}\right)$ stand for the two players' respective stage payoffs in $G(i)$ given $\theta$ and $\left(z_{1}^{\theta}, z_{2}^{\theta}\right)$;

- $\theta^{+}\left(z_{1}^{\theta}, z_{2}^{\theta}\right)=\left(i^{+}, t^{+}\right)$be the next stage state variable given $\theta$ and $\left(z_{1}^{\theta}, z_{2}^{\theta}\right)$ where $i^{+}$is defined according to the rules of $\Gamma_{\infty}^{\delta}$ and $t^{+}$is to be defined later;

- $\delta$ be the discount rate ;

- $\left(Y_{1}, Y_{2}\right)$ be a Markov equilibrium when it exists ;

- $\pi_{1}\left(Y_{1}, Y_{2} \mid \theta\right)$ and $\pi_{2}\left(Y_{1}, Y_{2} \mid \theta\right)$ refer to the players discounted equilibrium payoffs given an initial state $\theta$ and an equilibrium $\left(Y_{1}, Y_{2}\right)$.

Definition 1 Markov equilibria ${ }^{7}$ are such that:

$$
\begin{aligned}
& \pi_{1}\left(Y_{1}, Y_{2} \mid \theta\right)=\operatorname{Max}_{z_{1}^{\theta}}\left[G_{1}^{\theta}\left(z_{1}^{\theta}, y_{2}^{\theta}\right)+\delta \pi_{1}\left(Y_{1}, Y_{2} \mid \theta^{+}\left(z_{1}^{\theta}, y_{2}^{\theta}\right)\right)\right] \\
& \pi_{2}\left(Y_{1}, Y_{2} \mid \theta\right)=\operatorname{Max}_{z_{2}^{\theta}}\left[G_{2}^{\theta}\left(y_{1}^{\theta}, z_{2}^{\theta}\right)+\delta \pi_{2}\left(Y_{1}, Y_{2} \mid \theta^{+}\left(y_{1}^{\theta}, z_{2}^{\theta}\right)\right)\right]
\end{aligned}
$$

By construction, these Markov equilibria are refinements of Nash equilibria of $\Gamma_{\infty}^{\delta}$. They need not be perfect since they may depend on past moves through the variable $t$.

In the MT approach there is no such time variable, the GPS extension to infinitely repeated games provides some hints on how to design the time variable, this is done in the SME approach (see appendix for the formalizations of MT and GPS).

\section{The SME approach}

This approach relies on the following assumptions:

- the two players are exogeneously distinguished. One player is called player $L$ (for long term incumbent) and the other player is called player $S$ (for short term player to be seen as the hit and run player). No assumption is made at this point as regards the relative efficiency of $L$ versus $S$.

- an integer $n$ is exogeneously given and let $t=0,1 \ldots n$.

- when the game is in state $\theta=(i, 0)$, if $i^{+}=L$ then $t^{+}=0$ but if $i^{+}=S$ then $t^{+}=1$.

- when the game is in state $\theta=(S, t)$ with $1 \leq t<n$, if $i^{+}=S$ then $t^{+}=t+1$ but if $i^{+}=L$ then $t^{+}=0$.

- when the game is in state $\theta=(S, n), t^{+}=0$ whether $i^{+}=L$ or $S$.

\footnotetext{
${ }^{7}$ This system of equations is known as the Shapley recursive equations for recursive games (Shapley, 1953)
} 
For a given value of the parameter $n$, the following proposition gives sufficient conditions to obtain such a Markov equilibrium. Existence and uniqueness will be addressed later.

Proposition 2 Let $y_{L}$ and $y_{S}^{t}$ for $t \in\{0,1.2 \ldots n\}$ be a solution (if it exists) of the following system denoted $\Phi_{\delta}^{n}$ :

$$
\begin{aligned}
& -C_{L}\left(y_{S}^{t}\right)+v_{L}\left(y_{L}\right) \delta\left(1-\delta^{n-t}\right) /(1-\delta)=0 \quad \text { for } t \in\{0,1,2 \ldots n\} \\
& -C_{S}\left(y_{L}\right)+\sum_{t=1}^{t=n} \delta^{t} v_{S}\left(y_{S}^{t}\right)=0 \\
& \text { and } \\
& v_{L}\left(y_{L}\right) \geq 0 \\
& \sum_{t^{\prime}=n}^{t^{\prime}=n} \delta^{t^{\prime}-t} v_{S}\left(y_{S}^{t^{\prime}}\right) \geq 0 \quad \text { for } t \in\{1,2 \ldots n\} \\
& \text { but } \\
& \sum_{t^{\prime}=n}^{t^{\prime}=n} \delta^{t^{\prime}} v_{S}\left(y_{S}^{t^{\prime}}\right)<0 \\
& \quad \text { Then the following moves in } \Gamma_{\infty}^{\delta} \text { are a Markov equilibrium: } \\
& \quad \text { if } \theta=(L, 0) \text { player } L \text { plays } x_{L}=y_{L} \text { and player } S \text { plays out iff } x_{L} \leq y_{L} \\
& \quad \text { (in case player } L \text { moves out then player } S \text { also moves out }) ; \\
& \quad \text { if } \theta=(S, 0) \text { player } S \text { plays out then player } L \text { plays } x_{L}=y_{L} \text { and player } S \\
& \text { plays out iff } x_{L} \leq y_{L} \\
& \left.\quad \text { in case player } S \text { plays } x_{S} \text { player } L \text { moves out iff } x_{S} \leq y_{S}^{0}\right) ; \\
& \quad \text { if } \theta=(S, t) \text { with } t \neq 0 \text { player } S \text { plays } x_{S}=y_{S}^{t} \text { and player } L \text { plays out iff } \\
& x_{S} \leq y_{S}^{t} \quad \text { in case player } S \text { moves out then player } L \text { plays } x_{L}=y_{L} \text { and player } S \text { plays }
\end{aligned}
$$
$x_{S} \leq y_{S}^{t}$ out iff $\left.x_{L} \leq y_{L}\right)$.

Proof of this proposition is in the appendix.

Such an equilibrium may be interpreted as follows. ${ }^{8}$ The state $\theta=(L, 0)$ is an absorbing state in which $L$ remains a permanent incumbent using a stationary strategy, $L$ 's equilibrium stage payoff is non negative in that state. If he makes a mistake, $S$ moves in and the next stage is $\theta=(S, 1)$, then $S$ stays as an incumbent for $n$ stages using a non stationary strategy designed to make $L$ patient until $S$ moves out. Player $S$ 's total equilibrium payoff in $\theta=(S, 1)$ exceeds his entry cost in $\theta=(L, 0)$ given that $L$ made a mistake, furthermore $S$ 's total equilibrium payoff remains non negative along the way. At the state $\theta=(S, 0)$ player $S^{\prime} s$ best move is out because it is not worthwhile for him to make $L$ patient for $n+1$ stages. If $S$ makes a mistake along the way, $L$ moves in and the next state is $\theta=(L, 0)$.

A key feature of this equilibrium is that it is the long time incumbent's best strategy to wait until the hit and run player moves out and not to agressively fight against him. This is because it is the hit and run player's best strategy to eventually move out. Similarily as in GPS, one would like the length of the hit and run period (the parameter $n$ ) to be endogeneously determined. It will be proved later that player $S$ 's total equilibrium payoff in state $\theta=(S, 1)$ is increasing in $n$. It is proposed to select the most appropriate $n$ as the highest integer for which such a Markov equilibrium exists.

\footnotetext{
${ }^{8}$ These ideas go back to Louvert, 1998.
} 


\section{Properties of SME's for a given $n$}

This section addresses the mathematical properties of SME's for a given $n$. Some preliminary comments are in order.

Our attention is focused on the case $\delta$ close to 1 . It will be proved that if the system $\Phi_{\delta}^{n}$ has a solution it is necessarily unique. For mathematical simplicity, the proof is made on the limit system $\Phi_{1}^{n}$ derived from $\Phi_{\delta}^{n}$ when $\delta$ goes to 1 . The same arguments would apply to $\Phi_{\delta}^{n}$ when $\delta$ is close to 1 . Because $\Phi_{\delta}^{n}$ is continuous in $\delta$ its unique solution when $\delta$ goes to 1 converges to the unique solution of $\Phi_{1}^{n}$. The properties of the solution of $\Phi_{1}^{n}$ are studied and used to infer the properties of the solution of $\Phi_{\delta}^{n}$ which describes a SME.

To avoid ambiguity the solution of $\Phi_{1}^{n}$ when it exists is indexed by $n$ such as $y_{L}(n)$ and $y_{S}^{t}(n)$ for $t \in\{0,1,2 \ldots n\}$. The stage rent for player $L$ refers to $v_{L}\left(y_{L}(n)\right)$ and the total rent for player $S$ refers to $\Sigma_{t^{\prime}=1}^{t^{\prime}=n} v_{S}\left(y_{S}^{t^{\prime}}(n)\right)$.

Lemma 3 When $\delta$ goes to 1 the limit system $\Phi_{1}^{n}$ of the system $\Phi_{\delta}^{n}$ defined in Proposition 4 is such that:

$$
\begin{aligned}
& \text { for } t \in\{0,1,2 \ldots n\} \quad-C_{L}\left(y_{S}^{t}\right)+(n-t) v_{L}\left(y_{L}\right)=0 \\
& -C_{S}\left(y_{L}\right)+\Sigma_{t=1}^{t=n} v_{S}\left(y_{S}^{t}\right)=0 \\
& \text { for } t \in\{1,2 \ldots n\} \quad \begin{array}{l}
v_{L}\left(y_{L}\right) \geq 0 \\
\Sigma_{t^{\prime}=t}^{t^{\prime}=n} v_{S}\left(y_{S}^{t^{\prime}}\right) \geq 0
\end{array} \\
& \Sigma_{t^{\prime}=0}^{t^{\prime}=n} v_{S}\left(y_{S}^{t^{\prime}}\right)<0
\end{aligned}
$$

The proof of this lemma is straightforward.

Theorem $4 \Phi_{1}^{n}$ admits at most one solution for large enough $n$.

Proof of this theorem is in the appendix.

Theorem 5 If there exists a solution respectively in $\Phi_{1}^{m}$ and in $\Phi_{1}^{n}$ with $m>n$ then $y_{L}(m) \leq y_{L}(n)$.

Proof. Suppose $y_{L}(m)>y_{L}(n)$ then $v_{L}\left(y_{L}(m)\right)>v_{L}\left(y_{L}(n)\right)$. Since $C_{L}$ is strictly decreasing this implies for all $t \in\{0,1,2 \ldots n\}$ :

$$
y_{S}^{m-t}(m)<y_{S}^{n-t}(n)
$$

so that

$$
\Sigma_{t=n}^{t=0} v_{S}\left(y_{S}^{m-t}(m)\right)<\Sigma_{t=n}^{t=0} v_{S}\left(y_{S}^{n-t}(n)\right)
$$

For $t \in\{n+1, . . m\}$ we still have $y_{S}^{m-t}(m)<y_{S}^{0}(n)$ and, because of (5) we also certainly have $v_{S}\left(y_{S}^{0}(n)\right)<0$ then

$$
\Sigma_{t=m-1}^{t=0} v_{S}\left(y_{S}^{m-t}(m)\right) \leq \Sigma_{t=n}^{t=0} v_{S}\left(y_{S}^{m-t}(m)\right)
$$


Then

$$
\Sigma_{t=m-1}^{t=0} v_{S}\left(y_{S}^{m-t}(m)\right)<\Sigma_{t=n}^{t=0} v_{S}\left(y_{S}^{n-t}(n)\right)
$$

By construction the left hand side should be greater or equal to zero while the right hand side should be strictly negative thus a contradiction.

Theorem 6 Suppose there is a solution in $\Phi_{1}^{n}$ for all values of $n$ then:

$$
\begin{gathered}
\lim _{n \rightarrow \infty} v_{L}\left(y_{L}(n)\right)=0 \\
\lim _{n \rightarrow \infty} \sum_{1}^{n} v_{S}\left(y_{S}^{t}(n)\right)=C_{S}\left(v_{L}^{-1}(0)\right) \\
\lim _{n \rightarrow \infty} y_{S}^{1}(n)=x^{*}
\end{gathered}
$$

in which $x^{*}$ is uniquely defined as: $\Phi$

$$
\int_{x^{*}}^{C_{L}^{-1}(0)} v_{S}(x) \frac{d C_{L}}{d x}(x) d x=0
$$

Proof of this theorem is in the appendix.

Corollary 7 If there is a solution in $\Phi_{1}^{n}$ for arbitrarily large values of $n$ it is necessary that:

$$
v_{S}\left(x^{*}\right)+C_{S}\left(v_{L}^{-1}(0)\right) \leq 0
$$

and if

$$
v_{S}\left(x^{*}\right)+C_{S}\left(v_{L}^{-1}(0)\right)<0
$$

there is a solution for arbitrarily large values of $n$.

Proof. Consider the first part. Using (5), for all $n$ we have $v_{S}\left(y_{S}^{0}(n)\right)+$ $C_{S}\left(y_{L}(n)\right)<0$ so that at the limit we certainly have $v_{S}\left(x^{*}\right)+C_{S}\left(v_{L}^{-1}(0)\right) \leq 0$.

As for the second part the above theorem in fact proves that in the construction of theorem 6 for $n$ large enough $\hat{y}_{S}^{1}$ converges to $x^{*}$ as $\hat{y}_{L}$ goes to $v_{L}^{-1}(0)$; since $v_{S}\left(x^{*}\right)+C_{S}\left(v_{L}^{-1}(0)\right)<0$ it must be that (5) will be satisfied and a solution is obtained.

These results may be used to infer properties of a SME in $\Gamma_{\infty}^{\delta}$ with $\delta$ close to 1 . For a given $n$, the two systems $\Phi_{1}^{n}$ and $\Phi_{\delta}^{n}$ are close to each other. If $\Phi_{1}^{n}$ has a unique solution so does $\Phi_{\delta}^{n}$ and this solution is a SME of $\Gamma_{\infty}^{\delta}$. Observe that, as soon as $\delta<1, \Phi_{\delta}^{n}$ cannot have a solution for arbirarily large values of $n$. This is easily seen by contradiction considering the constraints that $\lim _{n \rightarrow \infty} \Sigma_{t=1}^{t=n} \delta^{t} v_{S}\left(y_{S}^{t}\right)=v_{S}\left(y_{S}^{1}\right)$ would have to satisfy. Denote by $n_{\delta}$ the largest integer for which $\Phi_{\delta}^{n}$ has a solution. The following corollary summarizes the main result of the paper: it provides a condition to obtain rent dissipation in $\Gamma_{\infty}^{\delta}$ when $\delta$ goes to 1 using SME as the solution concept. 
Theorem 8 Suppose $v_{S}\left(x^{*}\right)+C_{S}\left(v_{L}^{-1}(0)\right)<0$, then $\lim _{\delta \rightarrow 1} v_{L}\left(y_{L}\left(n_{\delta}\right)\right)=0$.

Proof. If $v_{S}\left(x^{*}\right)+C_{S}\left(v_{L}^{-1}(0)\right)<0, \Phi_{1}^{n}$ has a solution for arbitrarily large $n$, this proves that $\lim _{\delta \rightarrow 1} n_{\delta}=\infty$. Theorem 8 says that $\lim _{n \rightarrow \infty} v_{L}\left(y_{L}(n)\right)=0$. Since $\lim _{\delta \rightarrow 1} n_{\delta}=\infty$, whatever $n$ the solution of $\Phi_{1}^{n}$ and of $\Phi_{\delta}^{n}$ can be made arbitrarily closed so that $\lim _{\delta \rightarrow 1} v_{L}\left(y_{L}\left(n_{\delta}\right)\right)=0$.

\section{Economic analysis of the SME solution}

Recall the results for $\delta$ close to 1 . If $\Gamma_{\infty}^{\delta}$ has a SME of duration $n$, it is unique. If there are SME's with respective durations $n$ and $m$, the hit and run player should select the longest one to maximize its total rent. A condition is provided to obtain rent dissipation in $\Gamma_{\infty}^{\delta}$, in which case the hit and run player would at the limit stay indefinitely.

In the remaining part of this paper it will be assumed that the hit and run player selects the maximal duration for which $\Phi_{\delta}^{n}$ has a solution, letting $\delta$ go to 1. This seems as a natural assumption to make since by doing so the hit and run player selects the duration of his stay to his best advantage. In the concluding section this particular selection among SME's is further argumented.

By construction this defines the SME solution of the limit game $\Gamma_{\infty}^{1}$, the economic properties of which we want to now discuss.

Come back to symmetric and asymmetric entry games. Recall that a symmetric game is such that $v_{1}=v_{2}$ and $C_{1}=C_{2}$ and that an asymmetric game may be derived from a symmetric one such that $v_{1}=v_{2}+\Delta f$, in which $\Delta f$ is a constant, and $C_{1}=C_{2}$. If $\Delta f \geq 0$ player 1 is said to be strong and player 2 weak, and vice et versa.

Consider first the issue of rent dissipation in symmetric games. Theorem 8 proves that if there is rent dissipation with SME in $\Gamma_{\infty}^{1}$, the relative time horizon for $S$ can be extended to infinity, the stage rent $v\left(y_{L}\right)$ goes to zero and the total rent $\Sigma_{1}^{n} v\left(y_{S}^{t}(n)\right)$ goes to $C\left(v^{-1}(0)\right)$; this solution is consistent with both MT and GPS . Yet, one major difference should be pointed out. There need not always be rent dissipation in $\Gamma_{\infty}^{1}$.

This result suggests that the analysis of potential competition should be revisited : the issue of short time commitment is no longer sufficient and more attention should be given to other structural characteristics of the situation.

We proceed as follows. Firstly, the rent dissipation issue in symmetric games is discussed. Secondly, a taxonomy of competitive situations is introduced to analyze asymmetric ones.

\subsection{Rent dissipation in symmetric games}

Consider the special case in which $v$ and $C$ are linear functions. 
Proposition 9 If $v$ and $C$ are linear functions then rent dissipation prevails if $v_{S}\left(C_{L}^{-1}(0)\right)>C_{S}\left(v_{L}^{-1}(0)\right)$ while no rent dissipation prevails if $v_{S}\left(C_{L}^{-1}(0)\right)<$ $C_{S}\left(v_{L}^{-1}(0)\right)$.

Proof. The equation that defines $x^{*}$ is $\int_{x^{*}}^{C^{-1}(0)} v(x) \frac{d C}{d x}(x) d x=0$. Because of the linearity of the $v$ and $C$ functions, $x^{*}$ is the symmetric of $C^{-1}(0)$ with respect to $v_{S}^{-1}(0)$ so that $v_{S}\left(x^{*}\right)=-v_{S}\left(C_{L}^{-1}(0)\right)$. Then the result follows from corollary 9 .

Qualitatively speaking, this proposition says that the entry cost should be high enough with respect to the monopoly profit for rent dissipation to occur. It can be directly applied to the case of short run price commitment. This form of competition is illustrative of the very notion of contestability (Baumol et al 1982). Generally speaking, the stage game may be described as follows:

- firm $i$ is the incumbent and sets a price $p_{i}$;

- firm $j$ decides to enter or not, if it does enter it sets a price $p_{j}=p_{i}-s$ in which $s$ is a strictly positive function which may depend on $p_{i}$;

- if firm $j$ did not enter, firm $i$ payoff is $R\left(p_{i}\right)-f$ in which $R$ is the monopoly revenue function with $R^{\prime}>0$ and $R^{\prime \prime}<0$ and $f$ a stage fixed cost; ${ }^{9}$

- if firm $j$ did enter, firm $j$ payoff is $R\left(p_{i}-s\right)-f$, and firm $j$ will play first at the next stage;

- there are no commitments from one stage to the next one except the fact that the order of moves is endogeneouly determined. ${ }^{10}$

The symmetric entry game is thus defined with

$$
\begin{gathered}
v(p)=R(p)-f \\
C(p)=-(R(p-s)-f)
\end{gathered}
$$

In this framework contestability can be captured by letting $\varepsilon$ go to zero and one would expect that the incumbent price be forced to average cost i.e. to the price $p_{a c}$ such that $R\left(p_{a c}\right)-f=0$.Such is not the case with SME. Consider the simple case of constant switching cost that is, $s=c s t$.

Proposition 10 In an entry game with short run price commitments and constant switching costs, if this switching cost is close to zero, there is no rent dissipation.

Proof. Since $s$ is close to zero we may use linear approximations of the $v$ and $C$ functions around the value $p=p_{a c}$. Denote by $p_{l}$ the value of $p$ such that $C\left(p_{l}\right)=0$. We certainly have $p_{l}$ close to $p_{a c}$. According to proposition 12

\footnotetext{
${ }^{9}$ Ordinarily the revenue function $R(p)$ has a maximum (at the unconstrained monopoly price); we assume that $\varepsilon$ is small enough so that $C^{-1}(0)$ be less than this maximum so that $v$ is indeed increasing on the relevant range of analysis. This assumption may be relaxed without affecting the results.

${ }^{10}$ This form of competition has been formalized as an entry game in Ponssard (1991). There the simultaneous version was considered and a forward induction argument was used to select among equilibria. In the sequential version this argument is superfluous.
} 
the ratio $v\left(p_{l}\right) / C\left(p_{a c}\right)$ relative to 1 characterizes the situation. We may write $\left.v\left(p_{l}\right) / C\left(p_{a c}\right)=-\left(v\left(p_{l}\right)-v\left(p_{a c}\right) /\left(p_{l}-p_{a c}\right)\right) /\left(C\left(p_{a c}\right)-C\left(p_{l}\right)\right) /\left(p_{a c}-p_{l}\right)\right)$ so that $v\left(p_{l}\right) / C\left(p_{a c}\right)$ is close to $-v^{\prime}\left(p_{a c}\right) / C^{\prime}\left(p_{a c}\right)=R^{\prime}\left(p_{a c}\right) / R^{\prime}\left(p_{a c}-s\right)<1$ since $R^{\prime \prime}<0$.

This form of competition may be qualified as tough. A softer form of competition would correspond to a case in which the cost of entry is lower (and the static limit price higher). Eventually, rent dissipation would occur. A detailed example is given in the appendix.

\subsection{A taxonomy of competitive situations}

Rent dissipation may or may not occur in symmetric games. This generates an interesting taxonomy for the general case of asymmetric games in which one player is more efficient than the other.

Definition 11 A competitive situation is said to be one of

under-competition: if $L=$ weak and $S=$ strong there exists $n^{*}$ such that $\Phi_{1}^{n}$ has no solution for all $n>n^{*}$

(a less efficient incumbent can deter entry forever and make stationary positive profits);

selection: if $L=$ weak and $S=$ strong there always exist a solution in $\Phi_{1}^{n}$ for all $n$ large enough

but if $L=$ strong and $S=$ weak there exists $n^{*}$ such that $\Phi_{1}^{n}$ has no solution for all $n>n^{*}$

(a less efficient incumbent is not able to deter entry forever and make stationary positive profits, but a more efficient incumbent may);

excess-competition: whether $L=$ weak or $L=$ strong there always exist a solution in $\Phi_{1}^{n}$ for all n large enough

(if an incumbent were to choose to deter entry forever, it would have to dissipate all of its profits ).

A general comparative statics result always holds. If there is excess-competition in a symmetric game i.e., there is rent dissipation, then in the associated asymmetric game in which the long-term player is more and more efficient (increasing $\Delta f$ ), at some point, his rent will become strictly positive. Conversely, if there is under-competition in a symmetric game then in the associated asymmetric game in which the long-term player is less and less efficient (decreasing $\Delta f$ ), at some point, his rent will be fully dissipated.

Proposition 12 Take $v_{L}=v+\Delta f, v_{S}=v$ and $C_{L}=C_{S}=C$. Denote $H(\Delta f)=v_{S}\left(x^{*}\right)+C_{S}\left(v_{L}^{-1}(0)\right)$ then:

- if $H(0)<0$ there exists some $\Delta F>0$ such that for all $\Delta f>\Delta F$ we have $H(\Delta f)>0$

- if $H(0)>0$ then there exists some $\Delta F^{\prime}<0$ such that for all $\Delta f<\Delta F^{\prime}$ we have $H(\Delta f)<0$. 
Proof. Consider the first statement, in $H(\Delta f)=v_{S}\left(x^{*}\right)+C_{S}\left(v_{L}^{-1}(0)\right)$ observe that the first term does not depend on $\Delta f$ since $x^{*}$ is defined from the equation $\int_{x^{*}}^{C_{L}^{-1}(0)} v_{S}(x) \frac{d C_{L}}{d x}(x) d x=0$ is independant of $\Delta f$. As for the second term we certainly have $v_{L}^{-1}(0)$ strictly decreasing in $\Delta f$ so that, since $C_{S}$ is a decreasing function and since we are assuming that its derivative is uniformly bounded away from zero this provides the result. Reversing the argument we obtain the second statement.

Excess-competition refers to the case in which a difference in efficiency is not rewarded by an increase in profitability. Under-competition refers to the case in which a less efficient firm may sustain with a strictly positive profit. Selection is what one would expect under Schumpeterian competition. An economic illustration in which this taxonomy prevails is given in the appendix.

\section{Discussion}

The major result of this paper is that whether or not commitments are shortterm no longer dominates the other economic characteristics in the analysis of rent dissipation. To obtain rent dissipation, it is no longer sufficient that the discount factor goes to 1 .

These new results are obtained through a Markov equilibrium concept which embeds the hit and run idea. The results are derived under fairly general assumptions.

This approach suggests that potential competition is not very effective in markets in which competition is tough while it may if it is soft. In the former case the cost of entry is too high relative to the monopoly profit and, at equilibrium, a hit and run player cannot stay long enough to force the incumbent to average cost, in the latter case it may. This contradicts the standard results of contestability but it is well in line with more traditional views on entry.

The SME approach requires some further theoretical work. In this last section some open question are pointed out.

Question 1: There may be other Markov equilibria which are consistent with the proposed definition of the state variable. Full characterization would be helpful. This has been obtained with the MT approach.

Question 2: In corollary 9 it is suspected that the condition $v_{S}\left(x^{*}\right)+$ $C_{S}\left(v_{L}^{-1}(0)\right) \leq 0$ is not only necessary but also sufficient.

Question 3: For the proposed taxonomy, it should be true that in case of under-competition, when a weak player may remain with a strictly positive rent indefinitely, a strong player may also. This is more difficult than it may seem and does not follow from proposition 13.

Question 4: A more interesting issue concerns the fact that our assignment of player 1 and player 2 to the respective $L$ or $S$ positions may be considered as arbitrary. A more formal approach might be to have a preliminary stage at which each player decides how long he could stay, say $n_{1}$ for player 1 and $n_{2}$ for player 2 . The choices $n_{1}$ and $n_{2}$ are then revealed and an infinitly repeated game $\Gamma_{\infty}^{n_{1}, n_{2}}$ 
is played in which each player can only use hit and run strategies according to the number of stages decided at the preliminary stage. Using a Markov formalization similar to the present one, it is suspected that the equivalent of theorem 7 holds (i.e., given $n_{i}$ the best response $n_{j}\left(n_{i}\right)$ is the highest $n_{j}$ for which the entry game $\Gamma_{\infty}^{n_{1}, n_{2}}$ has an equilibrium). If this were indeed the case, our taxonomy could be stated as follows :

- selection: only the strong player would select to stay infinitely (the limit equilibria in $\Gamma_{\infty}^{n_{1}, n_{2}}$ with respect to large values of $\left(n_{1}, n_{2}\right)$ would have $n_{1}^{*}=$ $\infty, n_{2}^{*}<\infty$, where player 1 is the strong player);

- under-competition: either player could select to stay infinitely but if one does, the other would not wish to, the preliminary game would be similar to a battle of the sexes game (there would be two limit equilibria $\Gamma_{\infty}^{n_{1}, n_{2}}$ with $n_{1}^{*}=\infty, n_{2}^{*}<\infty$ and $\left.n_{1}^{*}<\infty, n_{2}^{*}=\infty\right)$;

- excess-competition: either player would select to stay infinitely whatever the other one does, the preliminary game would be similar to a prisonner dilemma game (formally $\Gamma_{\infty}^{n_{1}, n_{2}}$ would have no limit equilibrium with respect to large values of $\left(n_{1}, n_{2}\right)$, the best response $n_{1}\left(n_{2}\right)$ being $\infty$ and vice versa, while both equilibrium payoffs in a game $\Gamma_{\infty}^{n_{1}, n_{2}}$ would decrease as $\left(n_{1}, n_{2}\right)$ increases).

Answers to these questions would provide a better understanding of the SME concept and of the associated taxonomy.

\section{REFERENCES}

d'Aspremont C. and M. Motta (2000) Tougher competition or lower concentration: a trade-off for antitrust authorities, in G. Norman and J.F. Thisse, eds. Market structure and Competition policy: game theoretic approaches, Cambridge, UK: Cambridge University Press

Baumol, W., Panzar, J.C. and R.D. Willig (1982) Contestable Markets and Theory of Industry Structure, New York : Harcourt Brace, Jovanovich.

Boyer, M., Lasserre, P., Mariotti, T. and M. Moreaux, (2001) Preemption and rent dissipation under Bertrand Competition, working paper, CIRANO, January.

Brock, W. A., (1983) Contestable Markets and Theory of Industry Structure: a Review Article, Journal of Political Economy, 91, 1055-1066.

Dasgupta, P. and J. Stiglitz, (1986) Welfare and Competition with Sunk Costs, CEPR, London.

Dixit, A. K., (1980) The role of investment in entry deterrence, Economic Journal, 90, 95-106.

Eaton, B., and R. Lipsey, (1980), Exit barriers are entry barriers : the durability of capital as an entry barrier, Bell Journal of Economics, 10, 20-32.

Farrell, J. (1986), How effective is potential competition, Economic Letters, 20, 67-70.

Fudenberg, D., and Tirole, J. (1987), Understanding rent dissipation : on the use of game theory in industrial organization, American Economic Review $77,176-183$. 
Geroski, P. A. (1995), What do we know about entry? International Journal of Industrial Organization, 13, 421-40.

Gromb, D., J-P. Ponssard and D. Sevy, (1997), Selection in dynamic entry games, Games and Economic Behavior, 21, 62-84.

Henry, C. (1988), Concurrence potentielle et discrimination dans un modèle de duopole avec différenciation verticale, Mélanges économiques, essais en l'honneur d'Edmond Malinvaud, 289:313, Economica-EHESS, Paris.

Lahmandi, R., J-P. Ponssard and D. Sevy, (1996), Efficiency of dynamic quantity competition : a remark on Markov equilibria, Economic Letters, 50, 213-221.

Louvert, E., (1998), Solving entry games through extended Markov equilibria, in Modèles dynamiques de la concurrence imparfaite, doctoral dissertation, Ecole Polytechnique.

Maskin, E. and J. Tirole, (1988), A theory of dynamic oligopoly, Part I : overview and quantity competition with large fixed costs, Econometrica, 56-3, 549-569.

Maskin, E. and J. Tirole, (2001), Markov equilibria, I Observable Actions, Journal of Economic Theory, 100, 191-219.

Ponssard, J-P. (1991), Forward Induction and Sunk Costs Give Average Cost Pricing, Games Economic Behavior, 3, 221-236.

Scherer, F. M. (1992), International High-Technology Competition, Cambridge, Mass.: Harvard University Press.

Selten, R. (1978), The chain store paradox, The Theory and Decision, 9, 127-159.

Shapley, L. (1953), Stochastic games, Proc. Nat. Acad. Science, vol. 39, 1095-1100.

Shepherd, W. G. (1984), Contestability vs. Competition, The American Economic review, 74-4, 572-587.

Sutton, J. (1991) Sunk Costs and Market Structure, Cambridge, Mass.: MIT Press.

Wilson, R. (1992) Strategic Models of Entry Deterrence, in Handbook of Game Theory, vol. 1 (R.J. Aumann and S. Hart, eds.), Amsterdam, Elsevier Science.

\section{Apendix}

\subsection{Other Markow equilibria}

Each Markov approach amounts to interpret $\Gamma_{\infty}^{\delta}$ as a specific stochastic game (see figures 1 to 4 ).

The MT aproach (figure 2)

The strategies of the players depend only on the first component of $\theta$ that is, who is the current incumbent. Provided that $\delta$ is sufficiently close to one, 
$G\left(i^{1}\right) \stackrel{i=i^{2}}{\longrightarrow} G\left(i^{2}\right) \ldots . . . G\left(i^{k}\right) \ldots$

Figure 1: The game $\Gamma_{\infty}^{\delta}$

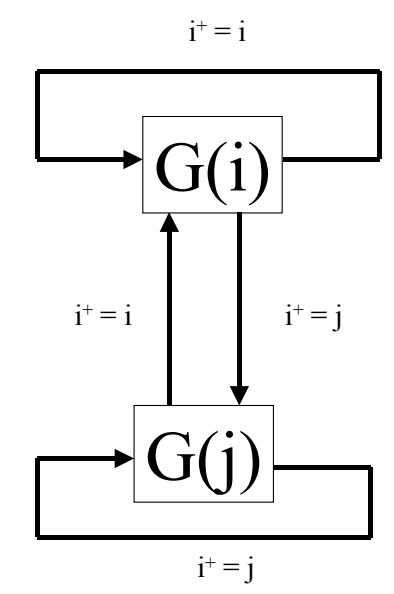

Figure 2: The game $\Gamma_{\infty}^{\delta}$ in the MT approach 


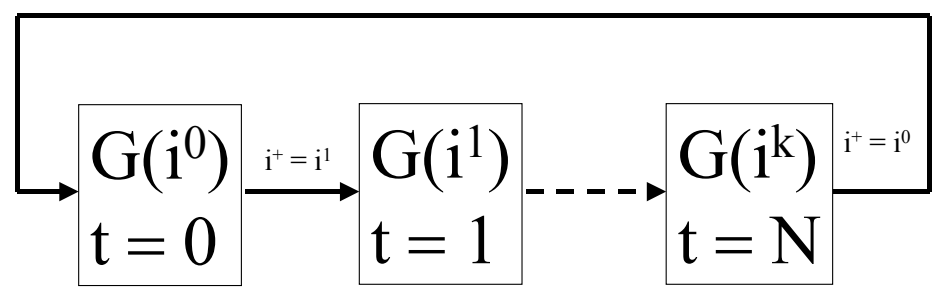

Figure 3: The game $\Gamma_{\infty}^{\delta}$ in the GPS approach

the following proposition holds (Maskin and Tirole, 1988) ${ }^{11}$ :

Proposition 13 Let $y_{1}$ and $y_{2}$ be the solution, proved to exist and to be unique, of the following system of two equations: ${ }^{12}$

$$
\begin{aligned}
& \text { for all } i \neq j \in\{1,2\} \quad-C_{i}\left(y_{j}\right)+\delta v_{i}\left(y_{i}\right) /(1-\delta)=0 \\
& \text { then the following moves in } G(i) \text { generate a Markov equilibrium: } \\
& \text { player } i \text { plays } x_{i}=y_{i} \\
& \text { player } j \text { plays out if and only if } x_{i} \leq y_{i} .
\end{aligned}
$$

This Markov equilibrium satisfies rent dissipation but not selection.

An equilibrium path may be interpreted as follows: anyone of the two players, whether it is the more efficient one or not, may remain as a permanent incumbent. In case he makes a mistake, the other player moves in and stays as the future permament incumbent.

The GPS approach (figure 3)

This refinement makes explicit use of the time variable. Let $N$ be an integer exogeneouly given. The following transition rule is adopted:

\footnotetext{
${ }^{11}$ Maskin and Tirole's analysis is carried out on a specific Cournot model but their Markov approach can be directly applied to the class of entry games defined in this paper. While they identify other Markow equilibria, the focus in their paper is on the one characterized by proposition 2 .

${ }^{12}$ In the following three propositions, we should more precisely write $y_{i}(\delta)$, the dependency of $y_{i}$ on the discount factor $\delta$ is left out to simplify the notations.
} 
- $t^{+}=t \bmod (N+1)$.

A Markov equilibria may be constructed as a direct extension of GPS for finite games. Denote $\Gamma_{k}$ a finite entry game where $k$ here refers to the maximal number of times the stage games $G(i)$ may be repeated. The notation $\Gamma_{k}(1)$ and $\Gamma_{k}(2)$ makes precise who is the initial incumbent in $\Gamma_{k}$. Observe that any such game $\Gamma_{k}\left(i^{1}\right)$ is a finite perfect information game so that it has a unique perfect equilibrium. Provided that $\delta$ is sufficiently close to one, the following proposition holds.

Proposition 14 In any asymmetric entry game, for all $\Delta f>0$ (i.e. player 1 is more efficient than player 2 ) let an integer $N$ and two sequences $y_{1}^{t}$ and $y_{2}^{t}$ for $t \in\{0,1,2 \ldots N\}$ be the solution, proved to exist and be unique, of the following system of equations:

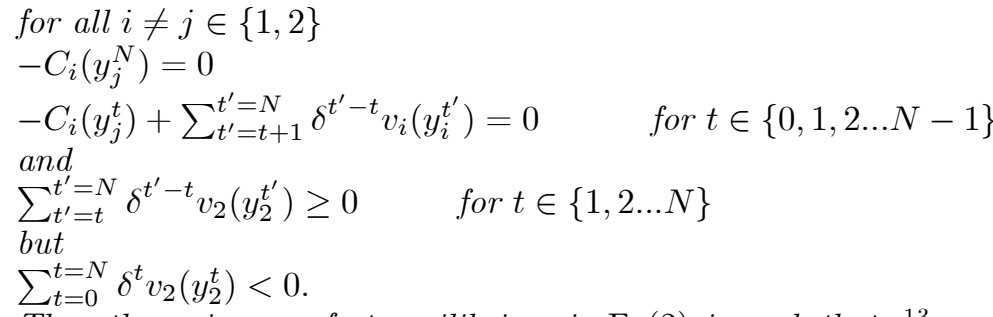

Then the unique perfect equilibrium in $\Gamma_{k}(2)$ is such that: ${ }^{13}$

for $1 \leq k \leq N$ player $i$ plays $x_{i}=y_{i}^{k}$ and player $j$ plays out if and only if $x_{i} \leq y_{i}^{k}$

for $k=0$ player 2 plays out, then player 1 plays $x_{1}=y_{1}^{0}$ and player 2 plays out if and only if $x_{1} \leq y_{1}^{0}$.

In the game $\Gamma_{k}(2)$ the less efficient player may maintain as a permanent incumbent if and only if $k \leq N$. This proposition (Gromb et al., 1997) allows to construct the unique perfect equilibrium of any game $\Gamma_{k}\left(i^{1}\right)$ whatever its length $k>N+1$ using a backward induction argument. Indeed, since the initial equilibrium move for player 2 in $\Gamma_{N+1}(2)$ is out then in terms of payoffs, we have $\Gamma_{N+1}(2) \equiv \Gamma_{N+1}(1)$ with a zero equilibrium payoff for player 2 , so that, $\Gamma_{N+2}(2) \equiv \Gamma_{1}(2)$ while $\Gamma_{N+2}(1) \equiv \Gamma_{1}(1)+\Gamma_{N+1}(1)$. Let $k=(N+1) q+r$ with $r<N+1$, then $\Gamma_{k}\left(i^{1}\right)$ will be played as a game $\Gamma_{r}\left(i^{1}\right)$ followed by $q$ times $\Gamma_{N+1}(1)$ games.

This equilibrium satisfies both rent dissipation and selection.

To construct the Markov equilibrium in $\Gamma_{\infty}^{\delta}$ consistent with the adopted transition rules, go as follows: decompose the game $\Gamma_{\infty}^{\delta}$ into finite sequences of $N+1$ stages, within each such sequences use the strategies of $\Gamma_{N+1}$, this is feasible since the state variable says where the players stand within each sequence. Clearly, if one player uses such a strategy, there is no way for the other to obtain a higher payoff than the one he gets through his Markov strategy.

\footnotetext{
${ }^{13}$ For simplicity only the equilibrium path is described, the best response after non equilibrium moves is easily completed.
} 


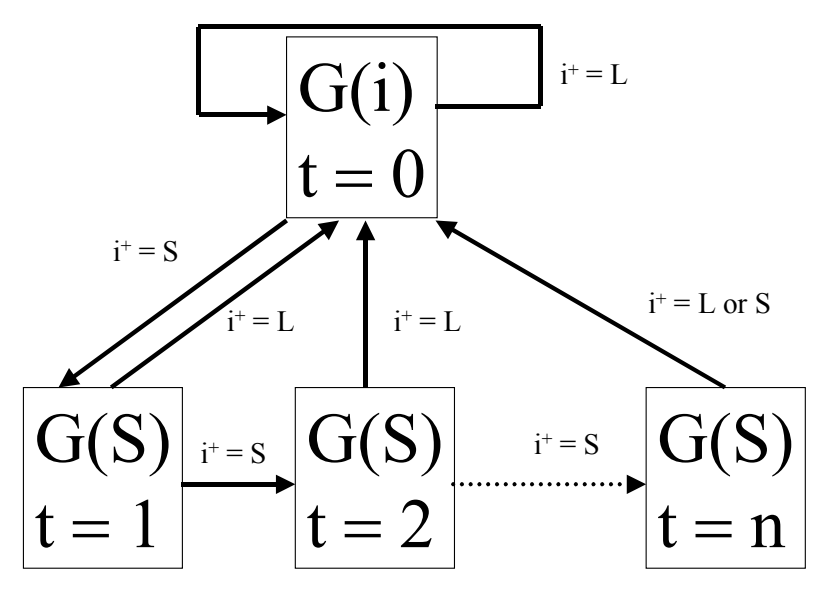

Figure 4: The game $\Gamma_{\infty}^{\delta}$ in the SME approach

This Markov equilibrium can be interpreted as follows: only the more efficient player may remain as a permanent incumbent, if he makes a mistake then the other player (the less efficient one to be seen as the hit and run player) moves in and stays in (at most $N$ stages) until $t=0$.

This equilibrium has at least three limitations. Firstly, the strategy of the efficient player should be stationary and not cyclical. Secondly, after a mistake, the number of stages the hit and run player may stay in should not depend on where the players stand on the cycle. Thirdly, it seems awkward to rely on a finite game to define the relevant $N$ used to construct the solution of an infinite horizon game. In this approach, the time variable says too much.

The SME approach (figure 4)

\subsection{Proofs}

Proof. (Proposition 2) Let $\left(Z_{L}, Z_{S}\right)$ be the Markov strategies as defined in the proposition. The associated paths are as follows:

- if $\theta=(L, 0)$ the path is : $\left(\left(y_{L}\right.\right.$, out $),\left(y_{L}\right.$, out $\left.), \ldots\right)$;

- if $\theta=(S, 0)$ the path is : $\left(\left(\right.\right.$ out,$y_{L}$, out $),\left(y_{L}\right.$, out $),\left(y_{L}\right.$, out $\left.), \ldots\right)$;

- if $\theta=(S, t)$ with $t \neq 0$ the path is: $\left(\left(y_{S}^{t}\right.\right.$, out $) \ldots\left(y_{S}^{n}\right.$, out $),\left(\right.$ out,$y_{L}$, out $),\left(y_{L}\right.$, out $\left.) \ldots\right)$;

The corresponding non negative discounted payoffs are easily computed as follows: $\pi_{L}\left(Z_{L}, Z_{S} \mid \theta=(L, 0)\right)=\pi_{L}\left(Z_{L}, Z_{S} \mid \theta=(S, 0)\right)=v_{L}\left(y_{L}\right) /(1-\delta)$ 


$$
\begin{aligned}
& \pi_{L}\left(Z_{L}, Z_{S} \mid \theta=(S, t)\right)=\delta^{n+1-t} \pi_{L}\left(Z_{L}, Z_{S} \mid \theta=(L, 0)\right) \\
& =v_{L}\left(y_{L}\right) \delta^{n+1-t} /(1-\delta) \text { for } t \in\{1,2 \ldots n\} \\
& \pi_{S}\left(Z_{L}, Z_{S} \mid \theta=(S, t)\right)=\Sigma_{t^{\prime}=t}^{t^{\prime}=n} \delta^{t^{\prime}-t} v_{S}\left(y_{S}^{t^{\prime}}\right) \quad \text { for } t \in\{1,2 \ldots n\} \\
& \quad \pi_{S}\left(Z_{L}, Z_{S} \mid \theta=(S, 0)\right)=\pi_{S}\left(Z_{L}, Z_{S} \mid \theta=(L, 0)\right)=0
\end{aligned}
$$

Part I : $Z_{L}$ is a best response to $Z_{S}$.

Let $\theta=(L, 0)$

- if player $L$ selects $x_{L} \leq y_{L}$ player $S$ moves out so that $\theta^{+}=(L, 0)$, then player $L$ discounted payoff is $v_{L}\left(x_{L}\right)+\delta \pi_{L}\left(Z_{L}, Z_{S} \mid \theta=(L, 0)\right)$

which is maximized at $x_{L}=y_{L}$ to be $\pi_{L}\left(Z_{L}, Z_{S} \mid \theta=(L, 0)\right)$;

- if player $L$ selects $x_{L}>y_{L}$ player $S$ moves in so that $\theta^{+}=(S, 1)$, then player $L$ discounted payoff is

$d_{L}\left(x_{L}\right)+\delta \pi_{L}\left(Z_{L}, Z_{S} \mid \theta=(S, 1)\right)=d_{L}\left(x_{L}\right)+\delta^{n+1} \pi_{L}\left(Z_{L}, Z_{S} \mid \theta=(L, 0)\right)<$ $\pi_{L}\left(Z_{L}, Z_{S} \mid \theta=(L, 0)\right)$ since $d_{L}\left(x_{L}\right) \leq 0$ and $\delta<1$;

- if player $L$ moves out player $S$ also moves out and the game ends with zero payoff for player $L$;

- this shows that $x_{L}=y_{L}$ is a best response.

Let $\theta=(S, t)$ for $t \in\{0,1,2 \ldots n\}$

- if player $S$ selects $x_{S} \leq y_{S}^{t}$ then by moving out player $L$ gets $\delta \pi_{L}\left(Z_{L}, Z_{S}\right.$ $\theta=(S, t))$ for $t \in\{0,1,2 \ldots n-1\}$, and $\delta \pi_{L}\left(Z_{L}, Z_{S} \mid \theta=(L, 0)\right)$ for $t=n$ so that his payoff may directly be written as $\delta^{n+1-t} \pi_{L}\left(Z_{L}, Z_{S} \mid \theta=(L, 0)\right)$, while by moving in he gets $-C_{L}\left(x_{S}\right)+\delta \pi_{L}\left(Z_{L}, Z_{S} \mid \theta=(L, 0)\right)$

since $-C_{L}\left(x_{S}\right) \leq-C_{L}\left(y_{S}^{t}\right)$ we have :

$-C_{L}\left(x_{S}\right)+\delta \pi_{L}\left(Z_{L}, Z_{S} \mid \theta=(L, 0)\right) \leq-C_{L}\left(y_{S}^{t}\right)+\delta \pi_{L}\left(Z_{L}, Z_{S} \mid \theta=(L, 0)\right)$ by construction $C_{L}\left(y_{S}^{t}\right)=v_{L}\left(y_{L}\right) \delta\left(1-\delta^{n-t}\right) /(1-\delta)$ and $\pi_{L}\left(Z_{L}, Z_{S} \mid \theta=\right.$ $(L, 0))=\delta v_{L}\left(y_{L}\right) /(1-\delta)$ so that

$-C_{L}\left(y_{S}^{t}\right)+\delta \pi_{L}\left(Z_{L}, Z_{S} \mid \theta=(L, 0)\right)=\delta^{n+1-t} \pi_{L}\left(Z_{L}, Z_{S} \mid \theta=(L, 0)\right)$

hence player $L^{\prime} s$ best response is to move out;

- if player $S$ select $x_{S}>y_{S}^{t}$ the same argument but with $-C_{L}\left(x_{S}\right)>$ $-C_{L}\left(y_{S}^{t}\right)$ shows that player $L^{\prime} s$ best response is to move in;

- if player $S$ moves out then, using the argument given for $\theta=(L, 0)$ it is clear that player $L$ should play $x_{L}=y_{L}$.

Part II : $Z_{S}$ is a best response to $Z_{L}$.

Let $\theta=(L, 0)$

- if player $L$ selects $x_{L} \leq y_{L}$ by moving out player $S$ gets $\pi_{S}\left(Z_{L}, Z_{S} \mid \theta=\right.$ $(L, 0))=0$, while if he moves in he gets $-C_{S}\left(x_{L}\right)+\delta \pi_{S}\left(Z_{L}, Z_{S} \mid \theta=(S, 1)\right)$. Since $-C_{S}\left(x_{L}\right) \leq-C_{S}\left(y_{L}\right)$ we have

$-C_{S}\left(x_{L}\right)+\delta \pi_{S}\left(Z_{L}, Z_{S} \mid \theta=(S, 1)\right) \leq-C_{S}\left(y_{L}\right)+\delta \pi_{S}\left(Z_{L}, Z_{S} \mid \theta=(S, 1)\right)$

by construction $C_{S}\left(y_{L}\right)=\Sigma_{t=1}^{t=n} \delta^{t} v_{S}\left(y_{S}^{t}\right)$ and $\pi_{S}\left(Z_{L}, Z_{S} \mid \theta=(S, 1)\right)=$ $\Sigma_{t^{\prime}=1}^{t^{\prime}=n} \delta^{t^{\prime}-1} v_{S}\left(y_{S}^{t^{\prime}}\right)$

so that

$-C_{S}\left(y_{L}\right)+\delta \pi_{S}\left(Z_{L}, Z_{S} \mid \theta=(S, 1)\right)=0$

hence player $S^{\prime} s$ best response is to move out;

- if player $L$ select $x_{L}>y_{L}$ the same argument but with $-C_{S}\left(x_{L}\right)>$ $-C_{S}\left(y_{L}\right)$ shows that player $S^{\prime} s$ best response is to move in; 
- if player $L$ selects out and player $S$ moves out the game ends and player $S$ gets 0 , if player $S$ selects $x_{S}>y_{S}^{0}$, by the Markov assumption player $L$ moves in and player $S$ discounted payoff is $d_{S}\left(x_{S}\right)+0 \leq 0$, if player $S$ selects $x_{S} \leq y_{S}^{0}$ player $L$ moves out and $\theta^{+}=(S, 1)$ but in that case player $S$ discounted payoff is strictly negative since $v\left(x_{S}\right) \leq v\left(y_{S}^{0}\right)$ and $\Sigma_{t^{\prime}=0}^{t^{\prime}=n} \delta^{t^{\prime}} v_{S}\left(y_{S}^{t^{\prime}}\right)<0$,

hence player $S^{\prime} s$ best response is to move out.

Let $\theta=(S, t)$ for $t \in\{0,1,2 \ldots n\}$

- if player $S$ selects moving out or $x_{S}>y_{S}^{t}$ (in which case player $L$ moves in) he gets 0 ;

- if player $S$ selects $x_{S} \leq y_{S}^{t}$ player $L$ plays out and player $S$ discounted payoff is $v_{S}\left(x_{S}\right)+\delta \pi_{S}\left(Z_{L}, Z_{S} \mid \theta=(S, t+1 \bmod n+1)\right)$

which is maximized at $x_{S}=y_{S}^{t}$ to be $\sum_{t^{\prime}=t}^{t^{\prime}=n} \delta^{t^{\prime}-t} v_{S}\left(y_{S}^{t^{\prime}}\right)$; by construction this expression is non negative if $t$ is different from 0 , and strictly negative if $t=0$, consequently player $S$ best response is $x_{S}=y_{S}^{t}$ for $t \in\{1,2 \ldots n\}$ but out for $t=0$.

Proof. ${ }^{14}$ (Theorem 4) The proof runs as follows. Firstly prove that conditions (1-2-3-4) of $\Phi_{1}^{n}$ have a unique solution. Secondly, check whether condition (5) is satisfied: if it is, the unique solution of $\Phi_{1}^{n}$ is obtained, if it is not $\Phi_{1}^{n}$ has no solution.

To prove the first part, for all $x_{L} \in\left[v_{L}^{-1}(0), C_{S}^{-1}(0)\right]$, define the function $W\left(x_{L}\right)=C_{S}\left(x_{L}\right)-\Sigma_{1}^{n} v_{S}\left(x_{S}^{t}\right)$ in which the sequence $\left(x_{S}^{t}\right)$ is derived from $x_{L}$ through (1) that is,

$$
-C_{L}\left(x_{S}^{t}\right)+(n-t) v_{L}\left(x_{L}\right)=0 \quad \text { for } t \in\{0,1,2 \ldots n\}
$$

then, show that $W\left(x_{L}\right)$ is negative (step 1) then positive (step 2) and that its derivative is strictly positive (step 3 ) so that there is a unique solution to the equation $W\left(x_{L}\right)=0$. Indeed:

Step 1: if $x_{L}=v_{L}^{-1}(0)$ then $W\left(x_{L}\right)<0$

In that case $x_{S}^{t}=C_{L}^{-1}(0)$ for all $t$ so that $W\left(v_{L}^{-1}(0)\right)=C_{S}\left(v_{L}^{-1}(0)\right)-$ $n v_{S}\left(C_{L}^{-1}(0)\right)$

by assumption $v_{S}\left(C_{L}^{-1}(0)\right)>0$ so that for $n$ large enough $W\left(v_{L}^{-1}(0)\right)<0$.

Step 2: if $x_{L}=C_{S}^{-1}(0)$ then $W\left(x_{L}\right)>0$

Since $C_{L}$ is strictly decreasing, the sequence $\left(x_{S}^{t}\right)$ is a strictly increasing sequence bounded by $C_{L}^{-1}(0)$. Since $v_{S}$ is strictly increasing this implies that $\Sigma_{1}^{n} v_{S}\left(x_{S}^{t}\right)$ is certainly negative for $n$ large enough so that $W\left(C_{S}^{-1}(0)\right)=-\Sigma_{1}^{n} v_{S}\left(x_{S}^{t}\right)$ is certainly positive.

Step 3: $\frac{d W}{d x_{L}}>0$

We have

$$
\frac{d W}{d x_{L}}=\frac{d C_{S}}{d x_{L}}-\Sigma_{t=1}^{t=n}\left(\frac{d v_{S}}{d x_{S}^{t}} \cdot \frac{d x_{S}^{t}}{d x_{L}}\right)
$$

\footnotetext{
${ }^{14} \mathrm{I}$ am indebted to Rida Laraki for providing the argument for this proof.
} 
Using (1) we get:

$$
\frac{d x_{S}^{t}}{d x_{L}}=(n-t) \frac{d v_{L}}{d x_{L}} / \frac{d C_{L}}{d x_{S}^{t}}
$$

By substitution it follows that:

$$
\frac{d W}{d x_{L}}=\frac{d C_{S}}{d x_{L}}-\frac{d v_{L}}{d x_{L}} \Sigma_{t=1}^{t=n}\left((n-t) \frac{d v_{S}}{d x_{S}^{t}} / \frac{d C_{L}}{d x_{S}^{t}}\right)
$$

By assumption $-\frac{d v_{S}}{d x_{S}^{t}} / \frac{d C_{L}}{d x_{S}^{t}}$ is uniformly bounded away from zero by $\varepsilon$ so that

$$
\frac{d W}{d x_{L}} \geq \frac{d C_{S}}{d x_{L}}+\frac{d v_{L}}{d x_{L}} \frac{n(n-1)}{2} \varepsilon
$$

Since $\frac{d v_{L}}{d x_{L}}$ is bounded away from zero and since $\frac{d C_{S}}{d x_{L}}$ is bounded away from $-\infty$ we certainly have $\frac{d W}{d x_{L}}>0$ for $n$ large enough.

Hence for a given $n$ large enough there is a unique solution to $W\left(x_{L}\right)=0$ that is, to (2). This solution is in $] v_{L}^{-1}(0), C_{S}^{-1}(0)$ [ so that (3) is also satisfied. Denote $\hat{y}_{L}$ this solution and $\left(\hat{y}_{S}^{t}\right)$ for $t \in\{0,1,2 \ldots n\}$ the associated sequence obtained through (1). Observe that (4) is satisfied as well : since $v_{S}$ is increasing the function $\Sigma_{t^{\prime}=t}^{t^{\prime}=n} v_{S}\left(\hat{y}_{S}^{t^{\prime}}\right)$ is bell shaped with respect to $t$ so for all $t$ we have:

$$
\Sigma_{t^{\prime}=t}^{t^{\prime}=n} v_{S}\left(\hat{y}_{S}^{t^{\prime}}\right) \geq \operatorname{Min}\left(\Sigma_{1}^{n} v_{S}\left(\hat{y}_{S}^{t}\right), v_{S}\left(\hat{y}_{S}^{n}\right)\right)=\operatorname{Min}\left(C_{S}\left(\hat{y}_{L}\right), v\left(C_{S}^{-1}(0)\right)>0\right.
$$

because $\hat{y}_{L}<C_{S}^{-1}(0)$ implies $C_{S}\left(\hat{y}_{L}\right)>0$ while $\hat{y}_{S}^{n}=v\left(C_{S}^{-1}(0)>0\right.$ by construction.

It is now a simple matter to check whether (5) holds or not. If it does a complete solution to $\Phi_{1}^{n}$ is obtained, if it does not there cannot be a solution for that value of $n$ since conditions (1) through (4) have a unique solution.

Proof. (Theorem 6) Parts 1 and 2 of the theorem are easily proved.

Indeed, suppose $v_{L}\left(y_{L}(n)\right) \geq \varepsilon>0$ for all $n$, then using (1) the sequence $\left(y_{S}^{t}(n)\right)$ is a strictly increasing sequence defined backwards from $y_{S}^{n}(n)=C_{L}^{-1}(0)$ so (4) cannot hold for large $n$ hence $\lim _{n \rightarrow \infty} v_{L}\left(y_{L}(n)\right)=0$. Then Part 2 follows from (2).

Part 3.

First of all, given that $\frac{d C_{L}}{d x}$ is bounded away from infinity and from zero and that $v_{S}(x)$ is bounded away from zero, there exists a unique $x^{*}<C_{L}^{-1}(0)$ such that

$$
\int_{x^{*}}^{C_{L}^{-1}(0)} v_{S}(x) \frac{d C_{L}}{d x}(x) d x=0
$$

For all $x \leq C_{L}^{-1}(0)$ define $F(x)=\int_{x}^{C_{L}^{-1}(0)} v_{S}(u) \frac{d C_{L}}{d u}(u) d u$, the function $F$ is such that $F(x)>0$ iff $x<x^{*}$. 
We now show the convergence of $y_{S}^{1}(n)$ to $x^{*}$.

Using (1) and (2) we get :

$$
\begin{aligned}
C_{S}\left(y_{L}(n)\right) v_{L}\left(y_{L}(n)\right) & =\Sigma_{t=1}^{t=n} v_{S}\left(y_{S}^{t}(n)\right) v_{L}\left(y_{L}(n)\right) \\
& =\Sigma_{t=1}^{t=n} v_{S}\left(y_{S}^{t}(n)\right)\left[C_{L}\left(y_{S}^{t-1}(n)\right)-C_{L}\left(y_{S}^{t}(n)\right)\right]
\end{aligned}
$$

When $v_{L}\left(y_{L}(n)\right.$ is small this non negative expression is close to $F\left(y_{S}^{1}(n)\right){ }^{15}$ This proves that $y_{S}^{1}(n)$ cannot be far below $x^{*}$. Using (2) and (5) for the two sequences $n$ and $n+1$, it is clear that $y_{S}^{1}(n+1)$ and $y_{S}^{1}(n)$ cannot be far appart either. More precisely:

$$
\left|y_{S}^{1}(n+1)-y_{S}^{1}(n)\right| \leq-\operatorname{Min}\left(\frac{d C_{L}}{d x}\left(y_{S}^{1}(n)\right), \frac{d C_{L}}{d x}\left(y_{S}^{0}(n)\right)\right) v_{L}\left(y_{L}(n)\right)
$$

Since $\frac{d C_{L}}{d x}$ is bounded away from infinity, $\lim _{n \rightarrow \infty}\left|y_{S}^{1}(n+1)-y_{S}^{1}(n)\right|=0$, this is enough to prove that $y_{S}^{1}(n)$ converges to some limit and this limit can only be $x^{*}$ since $\lim _{n \rightarrow \infty} C_{S}\left(y_{L}(n)\right) v_{L}\left(y_{L}(n)\right)=\lim _{n \rightarrow \infty} C_{S}\left(y_{L}(n)\right) \lim _{n \rightarrow \infty} v_{L}\left(y_{L}(n)\right)=$ $C_{S}(0) \cdot 0=0$.

\subsection{Economic illustrations of potential competition}

Two economic models of entry are analysed. In both models under-competition prevails when competition is tough in case of entry.

\subsection{Competition through short run price commitments}

Consider the specific price model detailed in Ponssard (1991), the switching cost $s$ is not constant. Still the situation remains one of under-competition when $s$ is small. But, if $s$ is not close zero, we may have excess-competition. How tough price competition is is the key factor.

More precisely, let $\omega$ be a parameter to be interpreted as a price cross elasticity. The demand $D_{i}$ to firm $i$ is defined as follows :

$$
\begin{array}{cc}
0 \leq p_{i} \leq p_{j}-\left(1-p_{j}\right) / \omega & D_{i}\left(p_{i}, p_{j}\right)=D_{i}^{m}\left(p_{i}\right)=1-p_{i} \\
p_{j}-\left(1-p_{j}\right) / \omega \leq p_{i} & D_{i}\left(p_{i}, p_{j}\right)=D_{i}^{d}\left(p_{i}, p_{j}\right) \\
p_{i} \leq p_{j}+\left(1-p_{j}\right) /(1+\omega) & =(1+\omega)\left(1-p_{i}+\omega\left(p_{j}-p_{i}\right)\right) /(1+2 \omega) \\
p_{j}+\left(1-p_{j}\right) /(1+\omega) \leq p_{i} & D_{i}\left(p_{i}, p_{j}\right)=0
\end{array}
$$

${ }^{15}$ Proof. Make the change of variable from $x_{S}$ to $u=C_{L}\left(x_{S}\right)$. As $t$ goes from 1 to $n, x_{S}$ increases from $y_{S}^{1}(n)$ to $y_{S}^{n}(n)$ and $u$ from $u^{1}(n)=C_{L}\left(y_{S}^{1}(n)\right)$ to $u^{n}(n)=C_{L}\left(y_{S}^{n}(n)\right)=0$ but $u^{t-1}(n)-u^{t}(n)$ remains $t$ independant and equals $v_{L}\left(y_{L}(n)\right)$, let $\Delta u(n)=v_{L}\left(y_{L}(n)\right)$.

We may then write

$$
v_{L}\left(y_{L}(n)\right) \Sigma_{t=1}^{t=n} v_{S}\left(y_{S}^{t}(n)\right)=\Sigma_{t=1}^{t=n} v_{S}\left(C_{L}^{-1}\left(u^{t}(n)\right)\right) \Delta u(n)
$$

For large values of $n$ we have

$$
\Sigma_{t=1}^{t=n} v_{S}\left(C_{L}^{-1}\left(u^{t}(n)\right)\right) \Delta u(n) \approx \int_{u^{1}(n)}^{0} v_{S}\left(C_{L}^{-1}(u)\right) d u=\int_{y_{S}^{1}(n)}^{C_{L}^{-1}(0)} v_{S}(x) \frac{d C_{L}}{d x}(x) d x
$$


The demand function is piece wise linear with a kink when the regime changes from a monopoly to a duopoly one. The higher $\omega$ the smaller the duopoly range in which $D_{i}=D_{i}^{d}$ and the tougher the price competition ( $\varepsilon$ close to zero corresponds to large $\omega)$.

Firm $i$ incurs a stage fixed cost $f$ if and only if it produces. There is no variable cost. Consequently player $i$ 's profit as a function of the prices $\left(p_{i}, p_{j}\right)$ writes:

if $D_{i}\left(p_{i}, p_{j}\right)>0 \quad \pi_{i}\left(p_{i}, p_{j}\right)=D_{i}\left(p_{i}, p_{j}\right) \cdot p_{i}-f$

if $D_{i}\left(p_{i}, p_{j}\right)=0 \quad \pi_{i}\left(p_{i}, p_{j}\right)=0$

The stage game $G(i)$ is :

- player $i$ is the incumbent, player $i$ may either select a move $p_{i}$ with $0 \leq$ $p_{i} \leq 1$, or move out i.e., he proposes no price ;

- if player $i$ selects $p_{i}$ then player $j$ may select $i n$, in this case this means that he sets a price $p_{j}$ which is his best response to $p_{i}$ in terms of revenue that is, without taking account of his fixed cost ; denote $p_{j}\left(p_{i}\right)$ this best response, then the players respective payoffs are $\left(\pi_{i}\left(p_{i}, p_{j}\left(p_{i}\right)\right), \pi_{j}\left(p_{i}, p_{j}\left(p_{i}\right)\right)\right)$; or he may select out with respective payoffs $\left(D_{i}^{m}\left(p_{i}\right) \cdot p_{i}-f, 0\right)$;

- etc.

The exit payoff which is $d_{i}\left(p_{i}\right)=\pi_{i}\left(p_{i}, p_{j}\left(p_{i}\right)\right)$ is certainly non positive for all relevant $p_{i}$.

Summing up the monopoly profit function $v$ is such that :

$$
v(p)=D^{m}(p) \cdot p-f=(1-p) p-f
$$

and the entry cost $C$ is defined as ${ }^{16}$

$$
C(p)=-\operatorname{Max}_{p_{j}}\left(D_{j}\left(p, p_{j}\right) \cdot p_{j}\right)+f
$$

Our attention will be limited to symmetric games. We want to investigate whether there is under or excess-competition depending on the two parameters $\omega$ and $f$. This depends on the sign of $v\left(p^{*}\right)+C\left(v^{-1}(0)\right)$ in which $p^{*}$ is defined by

$$
\int_{p^{*}}^{C^{-1}(0)} v(p) \frac{d C}{d p}(p) d p=0
$$

Observe that the function $C$ is not differentiable when the regime goes from the monopoly one to the duopoly one, but this is for only one point and has no bearing for the integral. Still we cannot obtain $p^{*}$ from an analytical formula and a numerical analysis has to be made to characterize the competitive situation. ${ }^{17}$ Figure 6 summarizes the results. In this table, $U C$ refers to under-competition, $E C$ refers to excess-competition.

\footnotetext{
${ }^{16}$ This makes the calculation of $C^{-1}(0)$ somewhat cumbersome.

${ }^{17}$ The corresponding calculations may be obtained from the author upon request.
} 


\begin{tabular}{|c|ccccccc|}
\hline $\boldsymbol{f}$ & & & & & & & \\
\hline 0,225 & UC & UC & UC & UC & UC & UC & UC \\
0,200 & UC & UC & UC & UC & UC & UC & UC \\
0,175 & EC & UC & UC & UC & UC & UC & UC \\
0,150 & EC & EC & EC & UC & UC & UC & UC \\
0,125 & EC & EC & EC & EC & EC & UC & UC \\
0,100 & EC & EC & EC & EC & EC & EC & UC \\
\hline $\boldsymbol{w}$ & 4 & 6 & 8 & 10 & 12 & 14 & 20 \\
\hline
\end{tabular}

Figure 5: The taxonomy for the price model

The positions of $U C$ and $E C$ in the table clearly suggests a pattern. The situation is always one of under-competition when $f$ is high (which is consistent with traditional economics) or when $w$ is large (which is not). The higher $f$ the lower $w$ to obtain under-competition. Such a context may be qualified as tough since the profit to be made is structurally low because of $f$ and the price competition is high because of $w$. On the opposite side the case of excesscompetition corresponds to simultaneous low values of $f$ and $w$, a context of less intense competition for the reverse reasons. This confirms the interpretation obtains with the previous example : structural factors related to the degree of toughness of competition do impact potential competition, the tougher the competition, the more likely it is that the incumbent may secure a positive rent.

\subsection{Competition through durable capital}

Consider the profit and entry cost functions defined as follows :

$$
\begin{aligned}
& v(x)=\pi^{m} x-f \\
& C(x)=\left(\pi^{m}-\pi^{d}\right)(H-x)
\end{aligned}
$$

Define symmetric and asymmetric games from these $v$ and $C$ functions.

This model may be interpreted as a reformulation ${ }^{18}$ of the Eaton and Lipsey model (1980). There firms compete through plants which become obsolete after $H$ units of time. The strategic decision for the incumbent consists in early replacement of its own plant. By doing so the incumbent prevent an entrant to preempt its market. Each time it sets a new plant, a firm incurs a fixed cost $f$. Operating costs are assumed to be zero. If both firms are in the market simultaneously, their duopoly flow of revenue is $\pi^{d}$ per unit of time. If only one is present, its flow of revenue is $\pi^{m}$. For consistency we certainly have $\pi^{m}>2 \pi^{d}$ and $\pi^{m} H \geq f$ so that $0 \leq v^{-1}(0)=f / \pi^{m} \leq H$. For simplicity also assume that

\footnotetext{
${ }^{18}$ See Gromb et al (1997) for details on this reformulation.
} 
$\pi^{d} H \leq f$. Note that $\Delta f$ may be interpreted as the difference in the fixed costs of the two firms.

In our framework a new stage game occurs each time a plant is set up, then $G(i)$ is such that:

- player $i$ is the incumbent, player $i$ may either select a move $x_{i}$ with $0 \leq$ $x_{i} \leq H=C^{-1}(0)$, i.e. he sets at what time he will replace his plant, or if he will move out that is, he will decide not to set a new plant ;

- if player $i$ selects $x_{i}$ then player $j$ may select $i n$, i.e. player $j$ will preempt player $i$ by setting up his own plant exactly before the selected time $x_{i}$ (with respective payoffs for $i$ and $j: d_{i}\left(x_{i}\right),-C_{j}\left(x_{i}\right)$; indeed player $j$ 's plant will be operating under a duopoly situation for the remaining life time of player $i$ 's plant that is, $H-x_{i}$ units of time ; this entry cost is the opportunity cost that need be substracted from player $j$ 's next stage profit when he will be playing as the incumbent); or player $j$ may select out (with self explanatory payoffs $\left.v_{i}\left(x_{i}\right), 0\right)$;

- etc.

Beware that the plant life time goes with the moves within a stage game $G(i)$ while the discrete time in $\Gamma_{\infty}^{\delta}$ goes with the setting of new plants.

Note that the exit payoff is $d_{i}\left(x_{i}\right)=\pi^{m} x_{i}+\pi^{d}\left(H-x_{i}\right)-f$ which is maximized and positive for $x_{i}=H$. Our Markov construction in state $(S, 0)$ should be adapted to let player $S$ capture this exit payoff rather than simply moving out. ${ }^{19}$

Corollary 15 The game of competition through durable capital has a SME for arbitrary large values of $n$ (i.e. there is rent dissipation for the long-term incumbent):

for $L=$ strong and $S=$ weak, iff $\quad \Delta f<\left(H \pi^{m}-f\right) \pi^{d} /\left(\pi^{m}-\pi^{d}\right)$;

for $L=$ weak and $S=$ strong, iff $\quad-\left(H \pi^{m}-f\right) \pi^{d} / \pi^{m}<\Delta f$.

Proof. Consider the first case that is, $v_{L}\left(x_{L}\right)=\pi^{m} x_{L}-f+\Delta f$ and $v_{S}\left(x_{S}\right)=\pi^{m} x_{S}-f$ and $C_{1}=C_{2}=C(x)=\left(\pi^{m}-\pi^{d}\right)(H-x)$. $H$.

Proposition 11 may be used. We have $v_{L}^{-1}(0)=(f-\Delta f) / \pi^{m}$ and $C^{-1}(0)=$

Then $-v_{S}\left(C^{-1}(0)\right)+C\left(v_{L}^{-1}(0)\right)=f-H \pi^{m}+\left(\pi^{m}-\pi^{d}\right)\left(H \pi^{m}-f\right) / \pi^{m}+$ $\Delta f\left(\pi^{m}-\pi^{d}\right) / \pi^{m}=-\pi^{d}\left(H \pi^{m}-f\right) / \pi^{m}+\Delta f\left(\pi^{m}-\pi^{d}\right) / \pi^{m}$

which is indeed negative iff $\Delta f<\left(H \pi^{m}-f\right) \pi^{d} /\left(\pi^{m}-\pi^{d}\right)$.

The second case that is, $v_{L}=\pi^{m} x-f$ and $v_{S}=\pi^{m} x_{i}-f+\Delta f$ and $C$ unchanged, is obtained through similar calculations.

Fix $\pi^{m}, H$ and $f$ and let $\pi^{d}$ and $\Delta f$ vary. Depending on the values of $\left(\pi^{d}, \Delta f\right)$ the type of competition lies in different zones that may be depicted in a diagram (see figure 5). This illustrates the taxonomy. The corresponding zones are interpreted as follows:

\footnotetext{
${ }^{19}$ In state $\theta=(S, 0)$ player $S$ plays $x_{S}=H$ and player $L$ moves out iff $x_{S} \leq y_{S}^{0}$. The sequence $\left(y_{S}^{t}\right)$ is now defined such that $-C_{L}\left(y_{S}^{t}\right)+(n+1-t) v_{L}\left(y_{L}\right)=0$ to take into account this change of strategies in $\theta=(S, 0)$. The other (in)equations in system $\Sigma_{1}$ are revised accordingly. This does not affect the mathematical properties of the SME.
} 


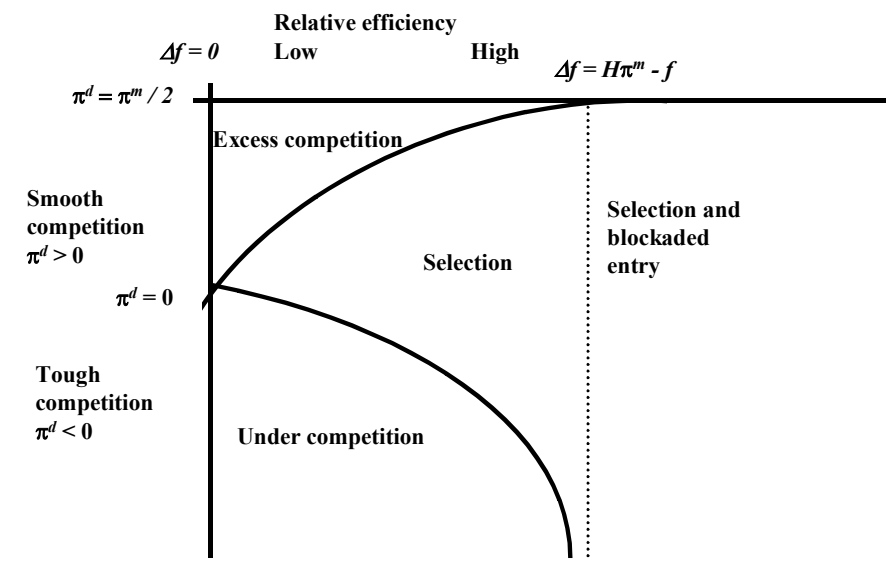

Figure 6: The taxonomy for the Eaton and Lipsey model

- selection is obtained whatever $\pi_{d}$ as long as $\Delta f$ is large enough ; observe that for $\Delta f>H \pi^{m}-f$ the least efficient firm is barred from the market anyway (blockaded entry);

- excess-competition prevails for $\pi_{d}>0$ and small enough $\Delta f$;

- under-competition prevails for $\pi_{d}<0$ and small enough $\Delta f$.

Rent dissipation does not always prevail. The toughness of competition in the case of entry is the structural factor that matters : it directly determines the ratio of the entry cost relative to the monopoly profit. With a negative duopoly revenue the incumbent is able to secure a positive stage rent.

With GPS, selection always occurs as soon as $\Delta f>0$. With SME it only occurs with $\Delta f$ large enough (except at the singular point $\pi^{d}=0$ ).

These results seem to make economic sense. 


\section{CESifo Working Paper Series}

(for full list see www.cesifo.de)

1120 Piotr Wdowinski, Determinants of Country Beta Risk in Poland, January 2004

1121 Margarita Katsimi and Thomas Moutos, Inequality and Redistribution via the Public Provision of Private Goods, January 2004

1122 Martin Peitz and Patrick Waelbroeck, The Effect of Internet Piracy on CD Sales: CrossSection Evidence, January 2004

1123 Ansgar Belke and Friedrich Schneider, Privatization in Austria: Some Theoretical Reasons and First Results About the Privatization Proceeds, January 2004

1124 Chang Woon Nam and Doina Maria Radulescu, Does Debt Maturity Matter for Investment Decisions?, February 2004

1125 Tomer Blumkin and Efraim Sadka, Minimum Wage with Optimal Income Taxation, February 2004

1126 David Parker, The UK's Privatisation Experiment: The Passage of Time Permits a Sober Assessment, February 2004

1127 Henrik Christoffersen and Martin Paldam, Privatization in Denmark, 1980-2002, February 2004

1128 Gregory S. Amacher, Erkki Koskela and Markku Ollikainen, Deforestation, Production Intensity and Land Use under Insecure Property Rights, February 2004

1129 Yin-Wong Cheung, Javier Gardeazabal, and Jesús Vázquez, Exchange Rate Dynamics: Where is the Saddle Path?, February 2004

1130 Alberto Alesina and Guido Tabellini, Bureaucrats or Politicians?, February 2004

1131 Gregory S. Amacher, Erkki Koskela, and Markku Ollikainen, Socially Optimal Royalty Design and Illegal Logging under Alternative Penalty Schemes, February 2004

1132 David M. Newbery, Privatising Network Industries, February 2004

1133 Charles Yuji Horioka, The Stagnation of Household Consumption in Japan, February 2004

1134 Eiji Fujii, Exchange Rate Pass-Through in the Deflationary Japan: How Effective is the Yen's Depreciation for Fighting Deflation?, February 2004

1135 Mark M. Spiegel and Nobuyoshi Yamori, Determinants of Voluntary Bank Disclosure: Evidence from Japanese Shinkin Banks, Febrary 2004 
1136 Robert Dekle and Kenneth Kletzer, Deposit Insurance, Regulatory Forbearance and Economic Growth: Implications for the Japanese Banking Crisis, February 2004

1137 Takatoshi Ito and Kimie Harada, Bank Fragility in Japan, 1995-2003, February 2004

1138 Kunio Okina and Shigenori Shiratsuka, Policy Duration Effect under Zero Interest Rates: An Application of Wavelet Analysis, February 2004

1139 Francine D. Blau and Lawrence M. Kahn, Do Cognitive Test Scores Explain Higher U.S. Wage Inequality?, February 2004

1140 Michael Rauscher, Economic Growth and Tax-Competing Leviathans, February 2004

1141 Ernst Fehr and Jean-Robert Tyran, Money Illusion and Coordination Failure, February 2004

1142 Ingo Vogelsang, Network Utilities in the U.S. - Sector Reforms without Privatization, March 2004

1143 Marc-Andreas Muendler, Estimating Production Functions When Productivity Change is Endogenous, March 2004

1144 Sascha O. Becker, Samuel Bentolila, Ana Fernandes, and Andrea Ichino, Job Insecurity and Children's Emancipation, March 2004

1145 Pascalis Raimondos-Møller and Alan D. Woodland, Non-Preferential Trading Clubs, March 2004

1146 Robert Fenge and Matthias Wrede, EU Regional Policy: Vertical Fiscal Externalities and Matching Grants, March 2004

1147 Chi-Yung Ng and John Whalley, Geographical Extension of Free Trade Zones as Trade Liberalization: A Numerical Simulation Approach, March 2004

1148 Marc-Andreas Muendler, Trade, Technology, and Productivity: A Study of Brazilian Manufacturers, 1986-1998, March 2004

1149 Eugene Beaulieu, Vivek H. Dehejia, and Hazrat-Omar Zakhilwal, International Trade, Labour Turnover, and the Wage Premium: Testing the Bhagwati-Dehejia Hypothesis for Canada, March 2004

1150 Giorgio Brunello and Francesca Gambarotto, Agglomeration Effects on EmployerProvided Training: Evidence from the UK, March 2004

1151 S. Brock Blomberg, Gregory D. Hess, and Athanasios Orphanides, The Macroeconomic Consequences of Terrorism, March 2004

1152 Bodo Sturm and Joachim Weimann, Unilateral Emissions Abatement: An Experiment, March 2004 
1153 Wolfgang Ochel, Welfare-to-Work Experiences with Specific Work-First Programmes in Selected Countries, March 2004

1154 Jan K. Brueckner and Eric Pels, European Airline Mergers, Alliance Consolidation, and Consumer Welfare, March 2004

1155 Aaron Tornell, Frank Westermann, and Lorenza Martínez, NAFTA and Mexico's Economic Performance, March 2004

1156 George Economides, Sarantis Kalyvitis, and Apostolis Philippopoulos, Do Foreign Aid Transfers Distort Incentives and Hurt Growth? Theory and Evidence from 75 Aid-recipient Countries, March 2004

1157 Robert Fenge and Volker Meier, Are Family Allowances and Fertility-related pensions Siamese Twins?, March 2004

1158 Bruno S. Frey, Simon Luechinger, and Alois Stutzer, Valuing Public Goods: The Life Satisfation Approach, March 2004

1159 Jerome L. Stein and Guay C. Lim, Asian Crises: Theory, Evidence, Warning-Signals, March 2004

1160 Romain Ranciere, Aaron Tornell, and Frank Westermann, Crises and Growth: A ReEvaluation, March 2004

1161 Assaf Razin and Efraim Sadka, Transparency, Specialization and FDI, March 2004

1162 Ludger Woessmann, How Equal Are Educational Opportunities? Family Background and Student Achievement in Europe and the United States, March 2004

1163 B.M.S. van Praag and Barbara E. Baarsma, Using Happiness Surveys to Value Intangibles: The Case of Airport Noise, March 2004

1164 Aaron Tornell, Frank Westermann, and Lorenza Martínez, The Positive Link Between Financial Liberalization, Growth, and Crises, March 2004

1165 Helge Berger and Carsten Hefeker, One Country, One Vote? Labor Market Structure and Voting Rights in the ECB, March 2004

1166 Clemens Fuest and Martin Kolmar, A Theory of User-Fee Competition, March 2004

1167 Friedrich Schneider and Robert Klinglmair, Shadow Economies around the World: What Do We Know?, April 2004

1168 Horst Raff and Nicolas Schmitt, Exclusive Dealing and Common Agency in International Markets, April 2004

1169 M. Hashem Pesaran and Allan Timmermann, Real Time Econometrics, April 2004

1170 Sean D. Barrett, Privatisation in Ireland, April 2004 
1171 V. Anton Muscatelli, Patrizio Tirelli and Carmine Trecroci, Can Fiscal Policy Help Macroeconomic Stabilisation? Evidence from a New Keynesian Model with Liquidity Constraints, April 2004

1172 Bernd Huber and Marco Runkel, Tax Competition, Excludable Public Goods and User Charges, April 2004

1173 John McMillan and Pablo Zoido, How to Subvert Democracy: Montesinos in Peru, April 2004

1174 Theo Eicher and Jong Woo Kang, Trade, Foreign Direct Investment or Acquisition: Optimal Entry Modes for Multinationals, April 2004

1175 Chang Woon Nam and Doina Maria Radulescu, Types of Tax Concessions for Attracting Foreign Direct Investment in Free Economic Zones, April 2004

1176 M. Hashem Pesaran and Andreas Pick, Econometric Issues in the Analysis of Contagion, April 2004

1177 Steinar Holden and Fredrik Wulfsberg, Downward Nominal Wage Rigidity in Europe, April 2004

1178 Stefan Lachenmaier and Ludger Woessmann, Does Innovation Cause Exports? Evidence from Exogenous Innovation Impulses and Obstacles, April 2004

1179 Thiess Buettner and Johannes Rincke, Labor Market Effects of Economic Integration The Impact of Re-Unification in German Border Regions, April 2004

1180 Marko Koethenbuerger, Leviathans, Federal Transfers, and the Cartelization Hypothesis, April 2004

1181 Michael Hoel, Tor Iversen, Tore Nilssen, and Jon Vislie, Genetic Testing and Repulsion from Chance, April 2004

1182 Paul De Grauwe and Gunther Schnabl, Exchange Rate Regimes and Macroeconomic Stability in Central and Eastern Europe, April 2004

1183 Arjan M. Lejour and Ruud A. de Mooij, Turkish Delight - Does Turkey's accession to the EU bring economic benefits?, May 2004

1184 Anzelika Zaiceva, Implications of EU Accession for International Migration: An Assessment of Potential Migration Pressure, May 2004

1185 Udo Kreickemeier, Fair Wages and Human Capital Accumulation in a Global Economy, May 2004

1186 Jean-Pierre Ponssard, Rent Dissipation in Repeated Entry Games: Some New Results, May 2004 